\title{
Editorial
}

\section{Academics must cut the tentacles that threaten to strangle them $^{\S}$}

\author{
Stephen Leeder ${ }^{1,2 *}$ \\ ${ }^{1}$ Emeritus Professor of Public Health and Community Medicine, The Menzies Centre for Health Policy and School of \\ Public Health, The University of Sydney. \\ ${ }^{2}$ Chair of the Board, and Director, Research and Education Network, Western Sydney Local Health District. \\ $\S$ This article was originally published in The Australian. November 04, 2015.
}

Keywords: Medical Journal of Australia; Australian Medical Association

Copyright: (C) 2015 Leeder S. This is an open access article distributed under the Creative Commons Attribution License, which permits unrestricted use, distribution, and reproduction in any medium, provided the original work is properly cited.

*Correspondence: stephen.leeder@sydney.edu.au

Cite this article as: Leeder S. Academics must cut the tentacles that threaten to strangle them. Anuradhapura Medical Journal 2015; 9: 21-22.

DOI: http://dx.doi.org/10.4038/amj.v9i2.7599

\begin{abstract}
Mark Robertson's reassurance that all is well in the world of academic publishing save for the occasional misunderstanding (The Australian, October 7) takes no account of widespread dissatisfaction within the research community, universities and academic libraries.
\end{abstract}

Robertson asserts that Wiley, an international publisher for which he works, reported a profit of only 11 per cent most recently. Like any international company it is difficult to know from financial statements pertaining to activities in Australia what the overall profit was. For example, based on research for her $\mathrm{PhD}$, Canadian academic Heather Morrison provided details of the enormous profits of several large scientific, technical and medical scholarly publishers.

She quotes profits as a percentage of revenue for commercial STM publishers in 2010 or early 2011. These include Elsevier with profits of $\$ 1.5$ billion on revenue of $\$ 3.4$ billion, or 44\%; Springer Science+Business Media, $\$ 636$ million on revenue of $\$ 1.9$ billion (33\%); John Wiley $\&$ Sons, $\$ 106$ million on revenue of $\$ 253$ million $(42 \%)$; and the academic division of Informa with profits of $\$ 100$ million on revenues of $\$ 313$ million (32\%).

Profits from academic publishing are immense, provoking widespread anger in universities, their libraries and research organisations. The Dutch government is in heavy conflict with Elsevier, a Dutch company, because of the huge payouts demanded for subscriptions to journals that it publishes. These are not minor misunderstandings but serious battles.
The business strategy adopted by the major publishers of scientific and scholarly writing is brilliant.

New knowledge generated from research is paid for from the public purse through research grants and academic salaries. Academics then give away their intellectual property to the publishers of their papers instead of licensing it. They then provide free peer review.

While a portion of intellectual property could justifiably be assigned to publishers, new knowledge should quickly become available to the sponsoring public and it doesn't. Instead, much essential free scientific water is bottled by publishers, then sold without compensation to the digger of the new well.

Simple diagnostics, however, do not apply. The publishing companies have found in universities a hunger for numerical data to measure performance.

The metrics of publication - how many times your paper has been cited and the prestige or impact factor of the journal you publish in - are used to judge you as an academic. Aggregated, the same metrics measure the performance of your institution.

High-ranking universities attract more international feepaying students. Academics acclaimed on these metrics gain promotion and preferred employment. Governments with no incentive to comprehend the complex social mission of universities beyond the publication metrics use them by default to determine university support. The system is closed and incestuous - and who can blame the publishers for making money from it? 
The plot thickens. Online publication has displaced print and accelerates the dissemination of new knowledge. Academic publishing has seen its share of shonky start-ups that have crashed and burned. The large established publishers have done deals with small academic associations and specialist journals that have kept their parents alive. The associations have found these arrangements to be financial havens and bless the publishers for their good fortune.

The medical profession has passed this way before where the largesse of pharmaceutical companies has supported research and paid for conference travel. Publishers claim that when they take over the production of a journal they assure editorial independence. It is true that they take no interest in the content of the journal, and why should they? But independence of research workers suffers when their intellectual produce is commodified and sold as part of a commercial enterprise.

The unfettered quest for new knowledge is crucial for innovation and progress. But academe and the research community have willingly embraced the octopus whose metric tentacles now threaten to strangle them.

Assuming that Malcolm Turnbull is serious about innovation, which depends critically on new knowledge, the Prime Minister would do well to inquire into how new knowledge is made, or not made, freely available. Australia could lead the world by insisting on open access and the decommodification of all new knowledge.

Now that would be innovative.

\section{Comment}

Professor Stephen Leeder, the editor-in-chief, of MJA (Medical Journal of Australia) was suddenly removed on May $1^{\text {st }}$ 2015 after criticizing the decision to outsource production of the journal to the global publishing giant Elsevier. The Australasian Medical Publishing Company (AMPCo), a wholly owned subsidiary of the Australian Medical Association (AMA), publishes the MJA.

Many supporters of the MJA and members of the AMA have expressed anger and distress over these actions. This information was not disclosed prior to AMA members. Most of the editorial advisory committee and two deputy editors resigned in protest.

The board of AMPCo and the president of the AMA claim that outsourcing was the only means of ensuring the financial future of the MJA and that the AMPCo Board had conducted a "due diligence" on Elsevier. Friends of the MJA claim that these actions were inadequately considered and ill judged. They are not in the best interests of the MJA and its contributors, reviewers and readers, who have, until now, contributed their expertise and time free of charge.

Friends of the MJA have called for a reversal of the decision to outsource production of the journal to Elsevier, for the resignation of the board of AMPCo, for the reinstatement of the editor-in-chief, Prof. Leeder and for full disclosure of the reasons for the decision to outsource and to sack the editor-in-chief.

AMA appeared to ignore the public record concerning Elsevier's unethical practices. "Elsevier put out a total of six publications between 2000 and 2005 that were sponsored by unnamed pharmaceutical companies and looked like peer reviewed medical journals, but did not disclose sponsorship, the company has admitted". At a 2009 court case in Australia where Merck \& Co. was being sued by a patient alleging that Merck had paid Elsevier to publish the Australasian Journal of Bone and Joint Medicine, which had the appearance of being a peer reviewed academic journal but in fact contained only articles favorable to Merck drugs. Merck described the journal as a "complimentary publication". In 2009, Elsevier released a statement, conceding that they have published journals on behalf of pharmaceutical clients, without proper disclosures.

This editorial and the comment showcase the perils that face academic publications and perhaps the benefit of low cost open access model.

\section{Adapted from http://www.friendsofmja.net.au \& Wikipedia}

Professor Sisira Siribaddana 